\title{
Toxoplasmose canina: aspectos clínicos e patológicos
}

\section{Canine toxoplasmosis : clinical and pathological aspects}

\author{
Katia Denise Saraiva Bresciani ${ }^{1 *}$; Alvimar José da Costa ${ }^{2}$; Italmar Teodorico \\ Navarro $^{3}$; Gilson Hélio Toniollo ${ }^{4}$; Cláudio Alessandro Massamitsu Sakamoto ${ }^{5}$; \\ Tiago Pereira Arantes ${ }^{6}$; Solange Maria Gennari ${ }^{7}$
}

\section{Resumo}

\begin{abstract}
Investigações relativas à toxoplasmose são fundamentais, tendo em vista o seu potencial zoonótico e sua patogenicidade em animais de produção e de companhia. O cão pode estar envolvido na transmissão mecânica da infecção por Toxoplasma gondii e apesar de não ser hospedeiro definitivo, tem papel epidemiológico relevante nesta protozoose. A elevada taxa de cães naturalmente infectados por T. gondii e a grande possibilidade destes se infectarem com este protozoário, justificam a importância de se atentar para a ocorrência desta enfermidade. Objetivou-se demonstrar por meio de revisão de literatura, alguns aspectos clínicos, epidemiológicos e patológicos da toxoplasmose na espécie canina.
\end{abstract}

Palavras-chave: Toxoplasma gondii, cães

\begin{abstract}
Inquiries about toxoplasmosis are essential because its zoonotic potential and pathogenicity in pets and production animals. The dog can be involved in the mechanical transmission of the infection by Toxoplasma gondii and in spite of not being the definitive host, it has an epidemiological role in this disease. The high rate of dogs naturally infected by $T$. gondii and the great possibility of adquiring this protozoan, justify the importance of attempting against for the occurrence of this illness. The aim of this article was to demonstrated through literature revision, some clinical aspects, epidemic and pathological of the toxoplasmosis in the canine species.
\end{abstract}

Key words: Toxoplasma gondii, dogs

1 Professora Assistente Doutora, Departamento de Apoio, Produção e Saúde Animal (DAPSA) da Faculdade de Odontologia de Araçatuba (FOA) - UNESP - Araçatuba, São Paulo (SP). E-mail: bresciani@fmva.unesp.br.

2 Professor Titular, CPPAR (Centro de Pesquisas em Sanidade Animal) da Faculdade de Ciências Agrárias e Veterinárias (FCAV), UNESP, Jaboticabal, SP.

3 Professor Associado, Departamento de Medicina Veterinária Preventiva, Centro de Ciências Agrárias, da Universidade Estadual de Londrina (UEL) - Londrina, Paraná (PR.).

4 Professor Adjunto, Departamento de Medicina Veterinária Preventiva e Reprodução Animal - FCAV - UNESP - Campus de Jaboticabal.

5 Médico Veterinário, Mestre, CPPAR, (FCAV), UNESP, Jaboticabal, SP.

${ }^{6}$ Médico Veterinário, Mestre, CPPAR, (FCAV), UNESP, Jaboticabal, SP.

7 Professora Associada, Departamento de Medicina Veterinária Preventiva e Saúde Animal da Faculdade de Medicina Veterinária e Zootecnia da Universidade de São Paulo, SP.

* Autor para correspondência 


\section{Introdução}

O Toxoplasma gondii é um protozoário coccídio, parasita intracelular obrigatório, com ciclo biológico complexo e que acomete praticamente todas as espécies animais de sangue quente (DUBEY; BEATTIE, 1988).

A etiologia da toxoplasmose foi elucidada quase que ao mesmo tempo, por Nicolle e Manceaux (1908) na Tunísia, no norte da África, e por Splendore (1908) na cidade de São Paulo, Brasil. A partir daí, este agente causal mereceu a atenção de pesquisadores de todo o mundo, sendo imprescindível enfatizar que a ciência brasileira contribuiu muito, desde a descrição da referida espécie, até o conhecimento de seu ciclo biológico (SPLENDORE, 1908; CARINI, 1911; MIGLIANO, 1912; CARINI; MACIEL, 1913, GARCIA et al., 2004).

A descoberta da natureza coccidiana do T. gondii, após a publicação das contribuições de Hutchison et al. (1970, 1971), Hutchinson, Dunachie e Work (1968), Witte e Piekarski (1970) e Frenkel (1973, 1990), representaram um marco na investigação e no esclarecimento da cadeia epidemiológica da toxoplasmose.

No seu ciclo, o T. gondii se apresenta sob duas formas evolutivas : os taquizoítos, estruturas de rápida multiplicação e que ocorrem na infecção aguda e os bradizoítos, confinados em cistos teciduais e presentes na infecção crônica. Já os oocistos, são o produto final da reprodução sexuada, formados somente no trato digestivo dos felídeos, seus hospedeiros definitivos (MILLER; FENKEL; DUBEY, 1972) que os eliminam juntamente com as fezes, onde por meio da esporogonia, tornam-se infectantes, sendo extremamente resistentes às condições ambientais, de acordo com Ylmaz e Hopkins (1972). Estas formas evolutivas estão disseminadas, principalmente, em áreas freqüentadas por gatos (RUIZ; FRENKEL; CERDAS, 1973).

A microscopia eletrônica tem propiciado diferenciação da ultra-estrutura dos gamontes
(SPEER; DUBEY, 2005) e detalhes de sua patogenia tem sido elucidados por meio da caracterização molecular (GARCIA et al., 2004, SCHWARZ et al., 2005). Estudos recentes confirmaram a hipótese antiga que a transmissão do parasito é mais eficiente quando gatos consomem cistos teciduais, pelo carnivorismo (DUBEY, 2006).

Em seres humanos, a transmissão transplacentária foi inicialmente demonstrada por Wolf e Cowen (1937), Wolf, Cowen e Paige (1939) e Sabin e Feldman (1948) que contribuíram fundamentalmente para o início do diagnóstico desta protozoose. Devese atentar para os fatores de risco de aquisição da infecção pré-natal bem como considerar sua patogenia e seqüelas (ORTEGA-BENITO, 2001; GIBBS, 2002; SOCCOL et al., 2003; BOYER et al., 2005; KRAVETZ; FEDERMAN, 2005; BACHMEYER et al., 2006; HUNG et al., 2007).

Por sua vez, Pinkerton e Weinman (1940) descreveram, com pioneirismo, casos de toxoplasmose em pessoas. Na vida pós-natal (SILVEIRA et al., 2001; SILVA et al., 2001; GIRALDI et al., 2002; ESCUISSATO et al., 2004), já foram relatados casos de alterações comportamentais, como déficit de atenção e esquizofrenia (LAFFERTY, 2005) reduzindo a qualidade de vida dos indivíduos (McALLISTER, 2005).

Por mais que a manifestação clínica desta doença seja infreqüente, estima-se que um terço, ou mais, da população humana possua anticorpos para o parasita (MONTOYA; LIESENFELD, 2004). Infecção oportunista é comum em pacientes com a síndrome da imunodeficiência adquirida (AIDS), podendo propiciar graves encefalites (SUKTHANA; CHINTANA; LEKKLA, 2000; HALONEN; TAYLOR; WEISS, 2001; KHETSURIANI; HOLMAN; ANDERSON, 2002; MAMIDI; DeSIMONE; POMERANTZ, 2002; CASTROSANSORES; GÓNGORA-BIACHI; GONZÁLEZMARTÍNEZ, 2004; PRADHAN; YADAV; MISHRA, 2007). 
Investigações relativas à toxoplasmose animal, são fundamentais, tendo em vista a sua transmissão ao homem e sua patogenicidade em animais de produção e de companhia (GARCIA et al., 1999a; 1999b, 1999c). Mais recentemente, a soroprevalência tem sido avaliada no Brasil, em animais silvestres, como gambás, capivaras e canídeos (YAI et al., 2003; CAÑÓN-FRANCO et al., 2003; GENNARI et al., 2004), apontando para a ocorrência de um ciclo silvestre importante.

Inicialmente o gene SAG2 foi utilizado como marcador no sistema de tipificação, baseado na técnica de Polimorfismo de Comprimento de Fragmentos de DNA gerados por Enzimas de Restrição sobre produtos Amplificados pela Reação em Cadeia pela Polimerase (PCR-RFLP), de acordo com Siblei et al. (1995) e Howe et al. (1997). Por meio desse marcador, amostras de T. gondii da Europa e América do Norte foram classificadas em três linhagens clonais predominantes, designadas como tipos I, II e III, ocorrendo nos animais e no homem (DARDÉ; BOUTEILLE; PESTREALEXANDRE, 1992). A maioria das amostras virulentas para camundongos pertencia ao tipo I, enquanto quase todos os isolados não virulentos eram caracterizados como dos tipos II ou III (HOWE; SIBLEY, 1995). Até 2005, empregava-se apenas este mesmo marcador nos estudos da ocorrência deste protozoário utilizando galinhas como indicadora dos isolados existentes no ambiente.

A correspondência entre virulência e padrão molecular da amostra pode não ser observada em todos os hospedeiros (GRIGG; SUZUKI, 2003). No Brasil, foram detectados os genótipos de T. gondii dos tipos I e III, apresentando este último, um variado padrão de virulência, em amostras de várias espécies de animais domésticos (SILVA et al., 2005, PENA et al., 2006, DUBEY et al., 2006, 2007a, 2007b).

Su, Zhang e Dubey (2006), desenvolveram mais nove marcadores para PCR-RFLP (c22-8, c29-2, L358, PK1, novo SAG2, BTUB, GRA6, SAG3 e Apico).para aumentar o poder de discriminação de linhagens arquétipos das atípicas. Com a adição dos marcadores SAG1 e SAG2, notou-se um padrão genético altamente diverso, com evidente distinção de populações de $T$. gondii em galinhas caipiras provenientes dos estados do Rio Grande do Sul e Pará (DUBEY et al., 2007a).

\section{Toxoplasmose Canina}

A toxoplasmose canina foi descrita pela primeira vez, na Itália, por Mello (1910) e no Brasil por Carini (1911) e Carini e Maciel (1913). Desde então, a toxoplasmose clínica e subclínica tem sido relatada nesta espécie animal (SALIBA; FUEHS; FREITAS, 1958; CASTRO et al., 1962; COSTA et al., 1978; PIMENTA et al., 1993; BRESCIANI et al., 2001; BRITO et al., 2002, DUBEY et al., 2006).

Devido ao elevado índice de animais naturalmente infectados por T. gondi, agente reconhecidamente oportunista, e sua correlação com doenças imunossupressivas, como a cinomose (MORETTI et al., 2002), deve-se atentar para a ocorrência desta enfermidade na espécie canina. O cão, apesar de não ser hospedeiro definitivo, contribui na disseminação mecânica desta protozoose (FRENKEL; PARKER, 1996; LINDSAY et al., 1997, SCHARES et al., 2005).

\section{Sinais clinicos}

Em inoculações experimentais, alguns animais permanecem assintomáticos, poucos adoecem e raramente ocorreram óbitos (KUHN et al., 1972; DUBEY, 1985). No entanto, foram descritas hipertermia, linfoadenopatia, distúrbios pulmonares e digestivos (OPPERMANN, 1971) e lesões oculares (ABREU et al., 2002).

Helley (1963) verificou que a infecção toxoplásmica em cadelas, em vários estágios gestacionais, pode provocar mortalidade dos filhotes do $4^{\circ}$ ao $75^{\circ}$ dias pós-nascimento. Cadelas no terço médio e final da gestação, experimentalmente 
infectadas com $T$. gondii, com $1,5 \times 10^{4}$ oocistos, por via oral ou $1,0 \times 10^{7}$ taquizoítos, por via subcutânea, apresentaram aborto e morte fetal (BRESCIANI et al., 1999; 2001). Posteriormente, estas alterações reprodutivas também foram observadas em fêmeas caninas naturalmente infectadas e que foram artificialmente reinfectadas aos 30 dias de prenhez com as mesmas formas evolutivas do referido protozoário em forma de inóculos de concentração idêntica a supracitada. Os filhotes originários dessas mães nasceram sorologicamente positivos, com títulos de anticorpos de 1:64 até 1:256, sendo aparentemente saudáveis, com exceção de um neonato que se mostrou debilitado. Foi possível detectar o parasito em amostras de saliva, leite e urina desses animais. Imunomarcação positiva de cistos e/ou taquizoítos foi evidente pela técnica de imunohistoquímica, em 23 órgãos dos animais experimentais evidenciando a importância da infecção pré-natal (BRESCIANI, 2003; BRESCIANI et al., 2004).

Outras alterações observadas em cães naturalmente infectados por esta doença, foram paresia espástica de membro pélvico (NESBIT; LOURENS; WILLIAMS, 1981; SUTER et al., 1984) e acometimento do corpo ciliar da retina (PIPER; COLE; SHADDUCK, 1970; HELLEY, 1970; KAVINSKI, 1980; GREENE, 1990; CARLTON; MC GAVIN, 1998).

\section{Epidemiologia}

Resultados de estudos sobre a freqüência da infecção toxoplásmica em cães, no Brasil, encontramse sintetizados na Tabela 1.

A ocorrência de anticorpos contra T. gondii, em cães atendidos na Policlínica Veterinária da Universidade Federal Fluminense, foi de 18,5\% (48/ 259) pelo teste de hemaglutinação direta, sendo que a análise identificou o acesso à rua desses animais como fator de risco para esta infecção (SOUZA PINTO et al., 2004a). Em cães com distúrbios neuromusculares, respiratórios e/ou gastrintestinais, do município de Uberlândia-MG, Mineo et al. (2001) obtiveram uma percentagem de $33 \%$ dos cães sororreagentes para $T$. gondii e 3,1\% com infecção simultânea para $T$. gondii e N. caninum.

A presença de anticorpos contra Neospora caninum e contra $T$. gondii foi investigada em 295 soros colhidos de cães provenientes da região Nordeste do Estado de São Paulo, não tendo sido detectada associação entre animais positivos para estes coccídios e a existência de neuropatias (VARANDAS et al., 2001). Perda da consciência e do movimento foram os principais sinais neurológicos associados à infecção toxoplásmica natural nesta espécie animal, descritos por Brito et al. (2002), em Botucatu, São Paulo. No Brasil, por meio da genotipagem de amostras cerebrais de cães com alterações nervosas, positivos para toxoplasmose, foram evidenciados os isolados tipo I e III (SILVA et al., 2005).

Cañón-Franco et al. (2004), em Monte Negro, Rondônia, verificaram que a soroprevalência contra T. gondii dentre os 157 cães avaliados atingiu 76,4\%. Nos cães com idade superior a dois anos, o percentual eleva-se para $85,5 \%$ e naqueles com idade inferior a 24 meses, a ocorrência foi menor que 50\%, evidenciando-se assim, a elevada exposição pósnatal ao T. gondii, naquele município. No mesmo estudo, observou-se maior percentagem de cães positivos $(84,9 \%)$ dentre aqueles com acesso à rua, em detrimento aos cães domiciliados (58,8\%). Outros autores, como Martinez-Maya (1986), Ahmad et al. (2001), Souza et al. (2003) também relataram tal diferença. Por outro lado, Souza Pinto et al. (2004b) observaram que o tipo de habitação pode ser considerado fator de risco, sinalizando que morar em casa, mesmo sem acesso à rua, aumenta a chance de infecção.

\section{Diagnóstico}

Considerando-se a sorologia como um método diagnóstico exequível, simples e economicamente 
viável, deve-se ressaltar que a RIFI é o método mais comumente utilizado, como pode ser constatado, na Tabela 1, onde a maioria dos estudos epidemiológicos empregaram esta técnica.

Estudo sobre a eficácia comparativa dos testes de aglutinação modificado, hemaglutinação e ELISA para a detecção de anticorpos contra $T$. gondii, em amostras séricas de cães, revelou que os três métodos podem ser recomendados na investigação epidemiológica desta zoonose (ZHANG et al., 2001).

Os parasitos apicomplexos $T$. gondii e $N$. caninum, muitos semelhantes morfologicamente, apenas podem ser diferenciados por peculiaridades ultra-estruturais, imunológicas (DUBEY; BEATTIE, 1988; LINDSAY; DUBEY, 1989) e moleculares (SAGER et al., 2006).

Deve-se ressaltar, no entanto, que a sorologia nem sempre é a melhor forma de se comprovar esta enfermidade. Exames histopatológicos de músculos atróficos realizados por Suter et al. (1984), em cinco cães com paresia espástica de membro pélvico, revelaram infiltração linfohistiocitária severa disseminada com cistos teciduais de Toxoplasma. $\mathrm{O}$ encontro do parasito, à biópsia, foi o melhor meio de diagnóstico de polimiosite poliradiculite válida para infecção toxoplásmica. Títulos de anticorpos séricos e de fluido céfalo - raquidiano (liqüor) não forneceram resultados conclusivos. No Brasil, Pimenta et al. (1993) descreveram um quadro de toxoplasmose visceral em três cães, de três a dez meses de idade. A lesão primária caracterizada por miosite intestinal necrosante associada a numerosos taquizoítos e correlação com sorologia positiva para $T$. gondii possibilitaram o diagnóstico. Cortes histopatológicos de lesões epidermais, oriundos de uma cadela com erliquiose crônica, no Rio de Janeiro, revelaram a presença do T. gondii, sendo este, o primeiro relato de localização cutânea desse agente (DUBEY et al., 2003).

Os órgãos mais comumente lesados pelo Toxoplasma, em cães, são pulmões e fígado (NEVES; FERRI; SALIBA., 1954; SALIBA; FUEHS; FREITAS, 1958; CASTRO et al., 1962;
CAPEN; COLE, 1966; SANTOS et al., 1968; GIRÃO, 1975, RHYAN; DUBEY, 1992). Opperman (1971) considera bastante difícil o isolamento deste protozoário em cães, por meio do bioensaio em camundongos. No entanto, Sogorb et al. (1972) destacaram o tropismo de $T$. gondii pelo cérebro no organismo canino. No entanto, a bioprova representa ótima ferramenta para detecção deste parasito (ABREU et al., 2002).

O exame histopatológico associado a técnica de imunohistoquímica tem sido amplamente utilizada no diagnóstico da infecçcão toxoplásmica em amostras de espécies silvestres e domésticas como minks (FRANK, 2001), golfinhos (JARDINE; DUBEY, 2002), gansos (DUBEY; HAMIR, 2002), lontras (MILLER et al., 2002) e em cães (PIMENTA et al., 1993; BRESCIANI et al., 2004).

Amostras de quatro cães sabidamente positivas para $T$. gondii, empregando-se imunohistoquímica e exames sorológicos, foram submetidas à PCR por Schatzberg et al. (2003). Dentre as amostras avaliadas, três mostraram-se positivas para o referido coccídio, sendo uma delas positiva também para $N$. caninum e uma quarta amostra foi considerada negativa, à luz desta técnica. Estes resultados demonstraram que a PCR é uma importante ferramenta complementar, mas que não substituirá, pelo menos por enquanto, os métodos convencionais de diagnóstico da toxoplasmose.

As cepas isoladas de T. gondii de gatos, cães e frangos no Brasil são dos tipos I e III, não sendo ainda identificado o tipo II (SILVA et al., 2005). No entanto, foi constatada combinação de diferentes alelos com determinação de 12 diferentes genótipos em amostras de cães, no Estado de São Paulo (DUBEY et al., 2007b).

\section{Tratamento}

Giraldi (2001) verificou in vitro que sulfonamidas, inibidores do dihidrofosfato redutase e timodilato sintetase e antibióticos ionóforos (lasolocida, narasina 
e salinomicina), macrolídeos, tetraciclinas e lisonaminas tem ação sobre taquizoítos e drogas como metronidazol, paramomicina e roxarsona exercem pouca ou nenhuma atividade sobre estas formas evolutivas de multiplicação rápida. Outros fármacos como pirimetamina, trimetropin + sulfonamida e doxiciclina (quadro 2), doxiciclina, azitromicina, minociclina e claritromicina podem ser empregados (LAPPIN, 2004).
Cloridrato de clindamicina pode ser utilizado na dosagem de 3 a $20 \mathrm{mg} / \mathrm{Kg}$, (Quadro 2) e também, na posologia de 12,5 a $25 \mathrm{mg} / \mathrm{Kg}, \mathrm{VO}$, a cada $12 \mathrm{~h}$ por uma a duas semanas para encurtar o tempo de eliminação do oocisto. Os sinais clínicos da toxoplasmose se resolvem dentro de dois a quatro dias com a administração deste medicamento (GREENE, 1990; LAPPIN, 2004).

Tabela 1. Ocorrência de anticorpos séricos contra o Toxoplasma gondii em cães de diferentes regiões brasileiras.

\begin{tabular}{|c|c|c|c|c|c|c|}
\hline Ano & Autor (es) & Local & $\begin{array}{c}\text { Prova } \\
\text { Sorológica }\end{array}$ & $\begin{array}{l}\mathrm{N}^{\circ} \text { de animais } \\
\text { examinados }\end{array}$ & $\begin{array}{l}\mathrm{N}^{0} \text { de animais } \\
\text { reagentes }\end{array}$ & $\begin{array}{c}\% \text { de } \\
\text { positividade }\end{array}$ \\
\hline 1981 & Ishizuka et al. & São Paulo & RIFI & 1256 & 801 & 63,80 \\
\hline 1985 & Salata et al. & Botucatu & RIFI & 47 & 30 & 63,80 \\
\hline 1985 & $\begin{array}{c}\text { Germano, Erbolato e } \\
\text { Ishizuka }\end{array}$ & Campinas & RIFI & 657 & 598 & 91,00 \\
\hline 1992 & $\begin{array}{c}\text { Guimarães, Ribeiro e } \\
\text { Lima }\end{array}$ & Belo Horizonte & RIFI & 243 & 114 & 47,30 \\
\hline 1998 & Domingues et al. & Jaboticabal & ELISA e RIFI & 120 & 96 & 80,0 \\
\hline 1998 & Cabral et al. & Uberlândia & ELISA & 289 & 152 & 52,70 \\
\hline $1999 a$ & Garcia et al. & Paraná & RIFI & 189 & 159 & 84,10 \\
\hline 2003 & $\begin{array}{l}\text { Coelho, Kobayashi e } \\
\text { Carvalho Junior }\end{array}$ & Rio de Janeiro & RIFI & 103 & 48 & 46,60 \\
\hline 2003 & Souza et al. & Paraná e São Paulo & MAT & 1244 & 265 & 21,30 \\
\hline 2004 & Canón-Franco et al. & Rondônia & RIFI & 157 & 120 & 76,40 \\
\hline 2004 & Reis et. al & Paraná & RIFI & 352 & 161 & 45,73 \\
\hline 2004 & Ragozo et al. & Paraíba & RIFI & 286 & 129 & 45,10 \\
\hline 2004 & Cavalcante et al. & Rondônia & RIFI & 177 & 138 & 77,90 \\
\hline 2004 & $\begin{array}{l}\text { Rosado, Guimarães, } \\
\text { Oliveira }\end{array}$ & Minas Gerais & RIFI & 246 & 153 & 62,20 \\
\hline 2004 & Mineo et al. & Minas Gerais & ELISA & 369 & 112 & 30,30 \\
\hline 2005 & Azevedo et al., 2005 & Paraíba & RIFI & 286 & 129 & 45,10 \\
\hline
\end{tabular}

Convenções: RIFI = Reação de Imunofluorescência Indireta; ELISA= Ensaio Imunoenzimático Indireto; MAT = Teste de Aglutinação Modificada.

Ácido folínico $(0,5$ a $5 \mathrm{mg} /$ dia $)$ pode ser empregado para prevenção das complicações hematológicas ocasionadas pelo tratamento com pirimetamina. Fármacos contra Toxoplasma em combinação com corticosteróides tópicos, orais ou parenterais, podem ser utilizados para evitar danos oculares secundários à inflamação. A recorrência é comum se a duração do tratamento for menor que quatro semanas e havendo imunodeficiência, o prognóstico é ruim (GREENE, 1990). 


\begin{tabular}{|c|c|c|c|c|c|}
\hline Drogas & $\begin{array}{c}\text { Doses } \\
(\mathrm{mg} / \mathrm{kg})\end{array}$ & $\begin{array}{c}\text { Intervalo } \\
\text { (horas) }\end{array}$ & $\begin{array}{l}\text { Período } \\
\text { (dias) }\end{array}$ & Via & Espécie animal \\
\hline Sulfadiazina & $60^{*}$ & 12 & dez a 14 & $\mathrm{O}$ & ambas \\
\hline Pirimetamina $^{* *}$ & 1 & 24 & sete a dez & $\mathrm{O}$ & cães \\
\hline Pirimetamina $^{* *}$ & 0,5 & 24 & sete a dez & $\mathrm{O}$ & gatos \\
\hline Clindamicina $^{* * *}$ & 40 & 12 & dez a 14 & $\mathrm{O}$ & ambas \\
\hline Fosfato de clindamicina & $12,5-25$ & 12 & 28 & IM & gatos \\
\hline Cloreto de clindamicina & $10-12$ & 12 & 28 & $\mathrm{O}$ & gatos \\
\hline Ácido fólico ${ }^{\#}$ & 5 & 24 & DT & $\mathrm{O}^{\# \#}$ & gatos \\
\hline Ácido folínico & 1 & 24 & DT & $\mathrm{O}^{\# \#}$ & gatos \\
\hline Sulfa-Trimetroprim ${ }^{a}$ & 15 & 12 & 28 & $\mathrm{O}$ & gatos \\
\hline
\end{tabular}

Quadro 2. Drogas e doses recomendadas na terapêutica da toxoplasmose canina e felina.

*Associada a sulfadiazina a dosagem pode ser reduzida para $30 \mathrm{mg} / \mathrm{kg}$; **Dosagem utilizada quando associada a sulfadiazina; *** Efetiva para T. gondii, droga de escolha para fêmeas gestantes; \#Deve-se escolher um destes componentes para minorar os efeitos tóxicos da pirimetamina;\#\#Suplementado a ração do gato; aUsada alternativamente para tratamento da toxoplasmose felina; DT - durante o tratamento; O - oral; IM - intramuscular.

Sinergismo pode ocorrer em sulfonamidas com pirimetamina, monesina ou toltrazuril e sulfonamidas com ormetropina, diaveridina e trimetropin, cloridrato de clindamicina e sulfa associada ao trimetropin (LAPPIN, 2004; GIRALDI, 2001).

\section{Controle e profilaxia}

Em cães não ocorre a fase enteroepitelial do T.gondii e estes são infectados pela ingestão de oocistos esporulados ou cistos teciduais. Assim, a coprofagia deve ser impedida e recomendá-se o fornecimento de produtos cárneos cozidos ou rações comercializadas. Deve-se atentar para a eliminação de hospedeiros paratênicos, como moscas e baratas, assim como evitar-se o contato com solo ou areia que possam estar contaminados com fezes de gatos, atentando para a limpeza diária da caixa de areia de felinos, a fim de reduzir a contaminação ambiental (GREENE, 1990, NAVARRO, 2001, LAPPIN, 2004), incluindo-se, também, neste contexto, o controle de natalidade em animais errantes, que pode contribuir para a redução da ocorrência desta importante zoonose (JITTAPALAPONG et al., 2007).

\section{Referências}

ABREU, C. B.; NAVARRO, I. T.; REIS, A. C. F.; SOUZA, M. S. B.; MACHADO, R.; MARANA, E. R. M.; PRUDÊNCIO, L. B.; MATTOS, M. R.; TSUTSUI, V. S. Toxoplasmose ocular em cães jovens inoculados com Toxoplasma gondii. Ciência Rural, Santa Maria, v.32, n.5, p.807-812, 2002.

AHMAD, F.; MAQBOOL, A.; MANFOOZ, A.; HAYAT, S. Serological survey of Toxoplasma gondii in dogs and cats. Pakistan Veterinary Journal, Faisalabad, v.21, p.3135, 2001. 
AZEVEDO, S. S.; BATISTA, C. S. A.; VASCONCELLOS, S. A.; AGUIAR, D. M.; RAGOZO, A. M. A.; RODRIGUES, A. A. R.; ALVES, C. J.; GENNARI, S. M. Seroepidemiology of Toxoplasma gondii and Neospora caninum in dogs from the state of Paraíba, Northeast region of Brazil. Research in Veterinary Science, London, v.79, n.1, p.5156, 2005.

BACHMEYER, C.; MOUCHNINO, G.; THULLIEZ, P.; BLUM, L. Congenital toxoplasmosis from an HIV-infected woman as a result of reactivation. The Journal of Infection, London, v.52, n.2, p.e55-e57, 2006.

BOYER, K. M.; HOLFELS, E.; ROIZEN, N.; SWISHER, C.; MACK, D.; REMINGTON, J.; WITHERS, S.; MEIER, P.; McLEOD, R. Risk factors for Toxoplasma gondii infection in mothers of infants with congenital toxoplasmosis: implications for prenatal management and screening. American Journal of Obstetrics and Gynecology, Saint Louis, v.192, n.2, p.564-571, 2005.

BRESCIANI, K. D. S. Estudo da reinfecção por Toxoplasma gondii (NICOLLE \& MANCEAUX, 1909) em cadelas gestantes naturalmente infectadas. 2003. Tese (Doutorado em Medicina Veterinária Preventiva) Faculdade de Ciências Agrárias e Veterinárias de Jaboticabal, Universidade Estadual Paulista, Jaboticabal.

BRESCIANI, K. D. S.; COSTA, A. J.; TONIOLLO, G. H.; KANAMURA, C. T.; LUVIZZOTO, M. C. R.; MORAIS, F. R.; PERRI, S. H. V. Transmissão transplacentária de Toxoplasma gondii em cadelas gestantes reinfectadas. In: CONGRESSO BRASILEIRO DE PARASITOLOGIA VETERINÁRIA, 13., 2004, Ouro Preto. Anais...Ouro Preto: Colégio Brasileiro de Parasitologia Veterinária, 2004. p. 214.

BRESCIANI, K. D. S.; COSTA, A. J.; TONIOLLO, G. H.; SABATINI, G. A.; MORAES, F. R.; PAULILLO, A. C.; FERRAUDO, A. S. Experimental toxoplasmosis in pregnant bitches. Veterinary Parasitology, Amsterdam, v.86, n.2, p.143-145, 1999.

BRESCIANI, K. D. S.; TONIOLLO, G. H.; COSTA, A. J.; SABATINI, G. A.; MORAES, F. R. Clinical, parasitological and obstetric observations in pregnant bitches with experimental toxoplasmosis. Ciência Rural, Santa Maria, v.31, n.6, p.1039-1043, 2001.

BRITO, A. F.; SOUZA, L. C.; SILVA, A. V.; LANGONI, H. Epidemiological and serological aspects in canine toxoplasmosis in animals with nervous symptoms. Memórias do Instituto Oswaldo Cruz, Rio de Janeiro, v.97, n.1, p.31-35, 2002.

CABRAL, D. D.; SILVA, D. A. O.; MINEO, J. R.; FERREIRA, F. A.; DURAN, F. P. Frequency of anti- Toxoplasma gondii antibodies in apparently healthy dogs of the city of Uberlândia - MG. Revista Brasileira de Parasitologia Veterinária, São Paulo, v.7, n.2, p.87-90, 1998.
CAÑÓN-FRANCO, W. A.; BERGAMASCHI, D. P.; LABRUNA, M. B.; CAMARGO, L. M.; SILVA, J. C.; PINTER, A.; GENNARI, S. M. Ocurrence of antiToxoplasma gondii antibodies in dogs in the urban area of Monte Negro, Rondônia, Brazil. Veterinary Research Communications, Amsterdam, v.28, n.2, p.113-118, 2004.

CAÑÓN-FRANCO, W. A.; YAI, L. E. O.; JOPPERT, A. M.; SOUZA, C. E.; D'AURIA, S. R. N.; DUBEY, J. P.; GENNARI, S. M. Soroprevalence of Toxoplasma gondii antibodies in the rodent cabybara (Hidrochoeris hidrocoeris) from Brazil. Journal of Parasitology, Lawrence, v.89, n.4, p.850, 2003.

CAPEN, C. C.; COLE, C. R. Pulmonary lesions in dogs with experimental and naturally occuring toxoplasmosis. Pathologia Veterinaria, Basel, v.3, n.1, p.40-63, 1966.

CARINI, A. Infection spontanée du pigeon et du chien due au toxoplasma cuniculi. Bulletin de la Societe de Pathologie Exotique, Paris, v.4, p.518-519, 1911.

CARINI, A.; MACIEL, J. Toxoplasmose naturelle du chien. Bulletin de la Societe de Pathologie Exotique, Paris, v.6, p.681-683, 1913.

CARLTON, W. W.; Mc GAVIN, M. D. Patologia veterinária especial de Thomson. 2.ed. Porto Alegre: ARTMED, 1998.

CASTRO, A. F. P.; CALDAS, A. D.; ROSA, C. A. S.; MELLO, D.; QUEIROZ, J. C. Isolamento de Toxoplasma gondii de cão e observações sobre casos clínicos. $O$ Biológico, São Paulo, v.28, n.2, p.46-50, 1962.

CASTRO-SANSORES, C. J.; GÓNGORA-BIACHI, R. A.; GONZÁLEZ-MARTÍNEZ, P. HIV-encephalopathy as initial manifestation of acquired immunodeficiency syndrome in Yucatán State, Mexico. Archives of Medical Research, Mexico, v.35, n.1, p.49-53, 2004.

CAVALCANTE, G. T.; AGUIAR, D. M.; CHIEBAO, D. P.; MEIRELES, L. R.; ANDRADE, H. F.; CAMARGO, L. M. A.; LABRUNA, M. B.; RUIZ, V. L. A.; GENNARI, S. M. Ocorrência de anticorpos anti- Toxoplasma gondii em humanos e animais domésticos da zona rural do Município de Monte Negro, Rondônia. em cães. In: CONGRESSO BRASILEIRO DE PARASITOLOGIA VETERINÁRIA, 13., 2004, Ouro Preto. Anais...Ouro Preto: Colégio Brasileiro de Parasitologia Veterinária, 2004. p.217.

COÊLHO, R. A.; KOBAYASHI, M.; CARVALHO JUNIOR, L. B. Prevalence of IgG antibodies specific to Toxoplasma gondii among blood donors in Recife, Northeast Brazil. Revista do Instituto de Medicina Tropical de São Paulo, São Paulo, v.45, n.4, p.229-231, 2003.

COSTA, A. J.; LUCAS, A.; MORAES, F. R.; KLOBUCARIC, A.; PAULILlO, A.C. Contribuição ao estudo da toxoplasmose canina. O Biológico, São Paulo, v.44, p.293297, 1978. 
DARDÉ, M. L.; BOUTEILLE, B.; PESTRE-ALEXANDRE, M. Isoenzime analysis of 35 Toxoplasma gondii isolates: biological and epidemiological implications. Journal of Parasitology, Lawrence, v.78, n.5, p.786-794, 1992.

DOMINGUES, L. M.; MACHADO, R. Z.; COSTA, M. T.; CARVALHO, C. S.; COSTA, A. J.; MALHEIROS, E. B. Canine toxoplasmosis: a comparative evaluation of the detection of anti-Toxoplasma gondii antibodies by the indirect immunoenzymatic assay (ELISA) and the indirect immunofluorescence reaction (IIF). Revista Brasileira de Parasitologia Veterinária, São Paulo, v.7, n.2, p.79- 85, 1998.

DUBEY, J. P. Comparative infectivity of oocysts and bradyzoites of Toxoplasma gondii for intermediate (mice) and definitive (cats) hosts. Veterinary Parasitology, Amsterdam, v.104, n.1/2, p.69-75, 2006.

. Toxoplasmosis in dogs. Canine Practice, Santa Barbara, v.28, p.7-28, 1985.

DUBEY, J. P.; BEATTIE, C. P. Toxoplasmosis of animals and man. Boca Raton: CRC, 1988.

DUBEY, J. P.; CHAPMAN, J. L.; ROSENTHAL, B. M.; MENSE, M.; SCHUELER, R. L. Clinical Sarcocystis neurona, Sarcocystis canis, Toxoplasma gondii, and Neospora caninum infections in dogs. Veterinary Parasitology, Amsterdam, v.137, n.1/2, p.36-49, 2006.

DUBEY, J. P.; HAMIR, A. N. Experimental toxoplasmosis in budgerigars (Melopsittacus undulatus). Journal of Parasitology, Lawrence, v.88, n.3, p.514-519, 2002.

DUBEY, J. P.; PIMENTA, A L.; ABBOUD, L. C. S.; RAVASANI, R. R.; MENSE, M. Dermatitis in a dog associated with an unidentified Toxoplasma gondii-like parasite. Veterinary Parasitology, Amsterdam, v.116, n.1, p.51-59, 2003.

DUBEY, J. P.; RAJAPAKSE, R. P. V. J.; WIJESUNDERA, R. R. M. K. K.; SUNDAR, N.; VELMURUGAN, G. V.; KWOK, O. C. H.; SU, C. Prevalence of Toxoplasma gondii in dogs from Sri Lanka and genetic characterization of the parasite isolates. Veterinary Parasitology, Amsterdam, v.146, n.34, p.341-346, $2007 \mathrm{~b}$.

DUBEY, J. P.; SU, C.; CORTES, J. A.; SUNDAR, N.; GOMEZ-MARIN, J. E.; POLO, L. J.; ZAMBRANO, L.; MORA, L. E.; LORA, F.; JIMENEZ, J.; KWOK, O. C. H.; SHEN, S. K.; ZHANG, X.; NIETO, A.; THULLIEZ, P. Prevalence of Toxoplasma gondii in cats from Colombia, South America and genetic characterization of $T$. gondii isolates. Veterinary Parasitology, Amsterdam, v.141, n.12, p.42-47, 2006.

DUBEY, J. P.; SUNDAR, N.; GENNARI, S. M.; MINERVINO, A. H. H.; FARIAS, N. A. R.; RUAS, J. L.; SANTOS, T. R. B.; CAVALCANTE, G. T.; KWOK, O. C. H.;
SUESCUISSATO, C.; AGUIAR, R. O.; GASPARETTO, E. L.; MÜLLER, N. L. Biologic and genetic comparison of Toxoplasma gondii isolates in free-range chickens from the northern Pará state and the southern state Rio Grande do Sul, Brazil revealed highly diverse and distinct parasite populations. Veterinary Parasitology, Amsterdam, v.143, n.2, p.182-188, 2007a.

ESCUISSATO, D. L.; AGUIAR R. O.; GASPARETTO, E. L.; MÜLLER, N. L. Disseminated toxoplasmosis after bone marrow transplantation: high-resolution CT appearance. Journal of Thoracic Imaging, Philadelphia, v.19, n.3, p.207209, 2004.

FRANK, R. K. An outbreak of toxoplasmosis in farmed mink (Mustela Vision S.). Journal of Veterinary Diagnostic Investigation, Columbia, v.13, n.3, p.245-249, 2001.

FRENKEL, J. K. Toxoplasmosis: parasite, life cycle, pathology and immunology. In: HAMMOND, D. M.; LONG, P. L. (Ed.). The Coccidia: eimeria, isospora, toxoplasma, and related genera. Baltimore: University Park Press, 1973. p.343-410.

. Transmission of toxoplasmosis and the role of immunity in limiting transmission and illness. Journal of the American Veterinary Medical Association, Schaumburg, v.196, n.2, p.233-240, 1990.

FRENKEL, J. K.; PARKER, B. B. An apparent role of dogs in the transmission of Toxoplasma gondii. The probable importance of xenosmophilia. Annals of the New York Academy of Sciences, New York, v.791, p.402-407, 1996.

GARCIA, J. L.; GENNARI, S. M.; NAVARRO, I. T.; MACHADO, R. Z.; SINHORINI, I. L. Toxoplasma gondii: isolation of tachyzoites rhoptries and incorporation into Iscom. Experimental Parasitology, San Diego, v.108, n.1/ 2, p.40-46, 2004.

GARCIA, J. L.; NAVARRO, I. T.; OGAWA, L.; OLIVEIRA, R. C. Soroepidemiologia da toxoplasmose em gatos e cães de propriedades rurais do Município de Jaguapitã, Estado do Paraná, Brasil. Ciência Rural, Santa Maria, v.29, n.1, p.99-104, 1999a.

Soroprevalência do Toxoplasma gondii em suínos, bovinos, ovinos e eqüinos e sua correlação com humanos, felinos e caninos, oriundos de propriedades rurais do Norte do Paraná- Brasil. Ciência Rural, Santa Maria, v.29, n.1, p.91-97, 1999b.

GARCIA, J. L.; NAVARRO, I. T.; OGAWA, L.; OLIVEIRA, R. C.; KOBILKA, E. Seroprevalence, epidemiology and ocular evaluation of human toxoplasmosis in a rural area in Jaguapitã (Parana), Brazil. Revista Panamericana de Salud Publica, Washington, v.6, n.3, p.157-163, 1999c. 
GENNARI, S. M.; CAÑÓN-FRANCO, W. A.; YAI, L. E. O.; SOUZA, S. L. P.; SANTOS, L. C.; FARIAS, N. A. R.; RUAS, J.; ROSSI, F. W.; GOMES, A. A. B. Seroprevalence of Toxoplasma gondii antibodies from wild canids from Brazil. Veterinary Parasitology, Amsterdam, v.121, n.3/4, p.337340, 2004.

GERMANO, P. M. L.; ERBOLATO, E. B.; ISHIZUKA, M. M. Estudo sorológico da toxoplasmose canina, pela prova de imunofluorescência indireta, na cidade de Campinas, 1981. Revista da Faculdade de Medicina Veterinária e Zootecnia da Universidade de São Paulo, São Paulo, v.22, n.1, p.53-58, 1985.

GIBBS, R. S. The origins of stillbirth: infectious diseases. Seminars in Perinatology, New York, v.26, n.1, p.75-78, 2002.

GIRALDI, J. H. Estudo da neosporose e da toxoplasmose em cães portadores de distúrbios neurológicos. 2001. Dissertação (Mestrado em Ciência Animal) - Universidade Estadual de Londrina, Londrina.

GIRALDI, N.; VIDOTTO, O.; NAVARRO, I. T.; GARCIA, J. L.; OGAWA, L.; KOBYLKA, E. Toxoplasma antibody and stool parasites in public school children, Rolândia, Paraná, Brazil. Revista da Sociedade Brasileira de Medicina Tropical, Rio de Janeiro, v.35, n.3, p.215-219, 2002.

GIRÃO, L. C. F. Estudo anátomo-patológico da toxoplasmose canina em Belo Horizonte (MG). 1975. Dissertação (Mestrado em Patologia) - Escola de Veterinária, Universidade Federal de Minas Gerais, Belo Horizonte.

GREENE, C. E. Infectious diseases of the dog and cat. Philadelphia: W. B. Saunders, 1990. p.819-829.

GRIGG, M. E.; SUZUKI, Y. Sexual recombination and clonal evolution of virulence in Toxoplasma gondii. Microbes and Infection, Paris, v.5, n.7, p.685-690, 2003.

GUIMARÃES, A. M.; RIBEIRO, M. F. B.; LIMA, J. D. Frequência de anticorpos anti-Toxoplasma gondii em cães de Belo Horizonte, Minas Gerais. Arquivo Brasileiro de Medicina Veterinária e Zootecnia, Belo Horizonte, v.44, n.1, p.67-68, 1992.

HALONEN, S. K.; TAYLOR, G. A.; WEISS, L. M. Gamma interferon-induced inhibition of Toxoplasma gondii in astrocytes is mediated by IGIP. Infection and Immunity, Washington, v.69, n.9, p.5573-5576, 2001.

HELLEY, D. M. Toxoplasmosis. Journal of Small Animal Practice, Oxford, v.10, p.627-629, 1970.

Toxoplasmosis. Journal of Small Animal Practice, Oxford, v.4, p.435-446, 1963.
HOWE, D. K.; HONORE, S.; DEROUIN, F.; SIBLEY, L. D. Determination of genotypes of Toxoplasma gondii strains isolated from patients with toxoplasmosis. Journal of Clinical Microbiology, Washington, v.35, n.6, p.14111414, 1997.

HOWE, D. K.; SIBLEY, L. D. Toxoplasma gondii comprises three clonal lineages: correlation of parasite genotype with human disease. Journal of Infectious Diseases, Chicago, v.172, n.6, p.1561-1566, 1995.

HUNG, C.C.; FAN, C.K.; SU, K.E.; SUNG, F.C.; CHIOU, H.Y.; GIL. V.; FERREIRA, M.D.A. C.; CARVALHO, J.M.; CRUZ, C.; LIN, Y.K.; TSENG, L. F.; SAO, K.Y.; CHANG, W. C.; LAN; H.S.; CHOU, S.H. Serological screening and toxoplasmosis exposure factors among pregnant women in the Democratic Republic of Sao Tome and Principe. Transactions of the Royal Society of Tropical Medicine and Hygiene, v. 101, n.2, p. 134-139, 2007.

HUTCHISON, W. M.; DUNACHIE, J. F.; SIIM, J. C.; WORK, K. Coccidian-like nature of Toxoplasma gondii. British Medical Journal, London, v.1, n.5689, p.142-144, 1970.

HUTCHISON, W. M.; DUNACHIE, J. F.; WORK, K. The faecal transmission of Toxoplasma gondii. Acta Pathologica et Microbioloica Scandinavica, Copenhagen, v.74, n.3, p.462-464, 1968.

HUTCHISON, W. M.; DUNACHIE, J. F.; WORK, K.; SIIM, J. C. The life cycle of the coccidian parasite, Toxoplasma gondii in the domestic cat. Transactions of the Royal Society of Tropical Medicine and Hygiene, London, v.65, n.3, p.380-399, 1971.

ISHIZUKA, M. M.; MIGUEL, O.; BROGLIATO, D. F. Incidência de infecção por Toxoplasma gondii em cães do município de São Paulo. Revista da Faculdade de Medicina Veterinária e Zootecnia da Universidade de São Paulo, São Paulo, v.18, n.2, p.161-165, 1981.

JARDINE, J. E.; DUBEY, J. P. Congenital toxoplasmosis in a Indo - Pacific bottlenose dolphin (Tursiops Aduncus). Journal of Parasitology, Lawrence, v.88, n.1, p.197-199, 2002.

JITTAPALAPONG, S.; NIMSUPAN, B; PINYOPANUWAT, N.; CHIMNOI, W.; KABEYA, H.; MARUYAMA, S. Seroprevalence of Toxoplasma gondii antibodies in stray cats and dogs in the Bangkok metropolitan area, Thailand. Veterinary Parasitology, Amsterdam, v.145, n.1-2, p.138-141, 2007.

KAVINSKI, L. C. Lesões oculares de toxoplasmose em cães clinicamente suspeitos de cinomose. Revista do Setor de Ciências Agrárias, Curitiba, v.2, p.67-70, 1980. 
KHETSURIANI, N.; HOLMAN, R. C.; ANDERSON, L. J. Burden of encephalitis-associated hospitalizations in the United States, 1988-1997. Clinical Infecious Diseases, Chicago, v.35, n.2, p.175-182, 2002.

KRAVETZ, J. D.; FEDERMAN, D. G. Toxoplasmosis in pregnancy. The American Journal of Medicine, New York, v.118, n.3, p.212-216, 2005.

KÜHN,D.; OPPERMANN, W.H.; RÖDEL,H.; CENTURIER, H. Experimentelle infektion von Hunden mit ToxoplasmaOozysten. Berliner und Munchener Tierarztliche Wochenschrift, Berlin, v.85, n.16, p.309-314, 1972.

LAFFERTY, K. D. Look what the cat dragged in: do parasites contribute to human cultural diversity? Behavioural Processes, Amsterdam, v.68, n.3, p.279-282, 2005.

LAPPIN, M. R. Doenças causadas por protozoários. In: ETTINGER, S. J.; FELDMAN, E. C. (Ed.). Tratado de medicina interna veterinária: doenças do cão e do gato. 5.ed. Rio de Janeiro: Guanabara Koogan, 2004. p.430-435.

LINDSAY, D. S.; DUBEY, J. P. In vitro development of Neospora caninum (Protozoa: Apicomplexa) from dogs. Journal of Parasitology, Lawrence, v.75, n.1, p.163-165, 1989.

LINDSAY,D. S.; DUBEY, J.P.; BUTLER, J. M.; BLAGBURN, B. L. Mechanical transmission of Toxoplasma gondii oocysts by dogs. Veterinary Parasitology, Amsterdam, v.73, n.1/2, p.27-33, 1997.

MAMIDI, A.; DeSIMONE, J. A.; POMERANTZ, R. J. Central nervous system infectious in individuals with HIV1 infection. Journal of Neurovirology, Philadelphia, v.8, n.3, p.158-167, 2002.

MARTINEZ-MAYA, J. J. Serological survey of toxoplasmosis in dogs in Mexico City and its importance in public health: summary of thesis. Veterinaria-Mexico, Mexico, v.17, p.332-333, 1986.

McALLISTER, M. M. A decade of discoveries in veterinary protozoology changes our concept of "subclinical" toxoplasmosis. Veterinary Parasitology, Amsterdam, v.132, n.3/4, p.241-247, 2005.

MELLO, V. Un cas de toxoplasmose du chien observé à Turin. Bulletin Society Pathology, Itália, v.28, p.359-363, 1910.

MIGLIANO, L. Um caso de toxoplasmose canina. Brasil Médico, Rio de Janeiro, v.26, p.273-274, 1912.

MILLER, M. A.; GARDNER, I. A.; PACKHAM, A.; MAZET, J. K.; HANNI, K. D.; JESSUP, D.; ESTES, J.; JAMESON, R.; DODD, E.; BARR, B. C.; LOWENSTINE, L. J.; GULLAND, F. M.; CONRAD, P. A. Evaluation of an indirect fluorescent antibody test (IFAT) for demonstration of antibodies to Toxoplasma gondii in the sea otter (Enhydra lutris). Journal of Parasitology, Lawrence, v.88, n.3, p.594-599, 2002.
MILLER, N. L.; FRENKEL, J. K.; DUBEY, J. P. Oral infections with Toxoplasma cysts and oocysts in felines, other mammals and birds. Journal of Parasitology, Lawrence, v.58, n.5, p.928-937, 1972.

MINEO, T. W. P.; SILVA, D. A. O.; COSTA, G. H. N.; VON ANCKEN, A. C. B.; KASPER, L. H.; SOUZA, M. A.; CABRAL, D. D.; COSTA, A. J.; MINEO, J. R. Detection of IgG antibodies to Neospora caninum and Toxoplasma gondii in dogs examined in a veterinary hospital from Brazil. Veterinary Parasitology, Amsterdam, v.98, n.4, p.239-245, 2001.

MINEO, T. W. P.; SILVA, D. A. O.; NÄSLUND, K.; BJÖRKMAN, C.; UGGLA, A.; MINEO, J. R. Toxoplasma gondii and Neospora caninum serological status of different canine populations from Uberlândia, Minas Gerais. Arquivo Brasileiro de Medicina Veterinária e Zootecnia, Belo Horizonte, v.56, n.3, p.414-417, 2004.

MONTOYA, J. G.; LIESENFELD, O. Toxoplasmosis. Lancet, London, v.363, n.9425, p.1965-1976, 2004.

MORETTI, L. D.; UENO, T. E.; RIBEIRO, M. R.; AGUIAR, D. M.; PAES, A. C.; PEZERICO, S. B.; SILVA, A. V. Toxoplasmose em cães co-infectados com o vírus da cinomose. Semina: Ciências Agrárias, Londrina, v.23, n.1, p.85-91, 2002.

NAVARRO, I T. Toxoplasmose . In: CONGRESSO DA ASSOCIAÇÃO BRASILEIRA DE VETERINÁRIOS ESPECIALISTAS EM SUINOS, 2001, Porto Alegre. Anais... Porto Alegre: 2001. (on line)

NESBIT, J. W.; LOURENS, D. C.; WILliAMS, M. C. Spastic paresis in two littermate pups caused by Toxoplasma gondii. Journal of the South African Veterinary Association, Pretoria, v.52, n.3, p.243-246, 1981.

NEVES, J. G.; FERRI, A. G.; SALIBA, A. M. Toxoplasmose canina. Veterinário, São Paulo, v.4, n.1, p.35-44, 1954.

NICOLLE. C. S.; MANCEAUX, L. Sur une infection à corps de Leishman (on organismes voisins), du gondii. Comptes Rendus l'Academie des Sciences, Montrouge, v.147, p.763-766, 1908.

OPPERMANN, W. H. Versuche zum experimentellen infection des hundes mit Toxoplasma - oozysten. 1971. Dissertation (Mestrado) - Institute fur Parasitologie des Fachbereiches Veterinarmedizin, Universität Berlin, Berlin.

ORTEGA-BENITO, J. M. Prenatal screening of congenital toxoplasmosis. Medicina Clinica, Barcelona, v.116, n.10, p.385-389, 2001.

PENA, H. F. J.; SOARES, R. M.; AMAKU, M.; DUBEY, J. P; GENNARI, S. M. Toxoplasma gondii infection in cats from São Paulo State, Brazil: seroprevalence, oocyst shedding, isolation in mice, and biologic and molecular characterization. Research in Veterinary Science, London, v.81, n.1, p.58-67, 2006. 
PIMENTA, A. L.; PIZA, E. T.; CARDOSO JUNIOR, R. B.; DUBEY, J. P. Visceral toxoplasmosis in dogs from Brazil. Veterinary Parasitology, Amsterdam, v.45, n.3/4, p.323326, 1993.

PINKERTON, H.; WEINMAN, D. Toxoplasma infection in man. Archives of Pathology, Chicago, v.30, p.374, 1940.

PIPER, R. C.; COLE, C. R.; SHADDUCK, J. A. Natural and experimental ocular toxoplasmosis in animals. American Journal of Ophtalmology, Chicago, v.69, n.4, p.662-668, 1970.

PRADHAN, S.; YADAV, R.; MISHRA, V. N. Toxoplasma meningoencephalitis in HIV-seronegative patients: clinical patterns, imaging features and treatment outcome. Transactions of the Royal Society of Tropical Medicine and Hygiene, London, v.101, n.1, p.25-33, 2007.

RAGOZO, A. M. A.; AZEVEDO, S. S.; VASCONCELLOS, S. A.; BATISTA, C. S. A.; AGUIAR, D. M.; RODRIGUES, A. A. R.; ALVES, C. J.; GENNARI, S. M. Toxoplasma gondii em cães na cidade de Campina Grande, Paraíba: soroepidemiologia e fatores de risco. In: CONGRESSO BRASILEIRO DE PARASITOLOGIA VETERINÁRIA, 13., 2004, Ouro Preto. Anais... Ouro Preto: Colégio Brasileiro de Parasitologia Veterinária, 2004. p.217.

REIS, C. R.; REIS, H. R.; GONÇALVES, D. D.; LOPES, F. M. R.; CARLETTI, R. T.; SILVA FILHO, M. F.; FREIRE, R. L.; NAVARRO, I. T. Levantamento sorológico da toxoplasmose em cães de Bela Vista do Paraíso - Paraná Brasil. In: CONGRESSO BRASILEIRO DE PARASITOLOGIA VETERINÁRIA, 13., 2004, Ouro Preto. Anais...Ouro Preto: Colégio Brasileiro de Parasitologia Veterinária, 2004.p.211.

RHYAN, J.; DUBEY, J. P. Toxoplasmosis in an adult dog with hepatic necrosis and associated tissue cysts and tachyzoites. Canine Practice, Santa Barbara, v.17, n.1, p.6-10, 1992.

ROSADO, I. R.; GUIMARÃES, A. M.; OLIVEIRA, T. M. F. S. Prevalência de anticorpos anti-Toxoplasma gondii em cães atendidos em clínicas veterinárias de Lavras, Minas Gerais. In: CONGRESSO BRASILEIRO DE PARASITOLOGIA VETERINÁRIA, 13., 2004, Ouro Preto. Anais...Ouro Preto: Colégio Brasileiro de Parasitologia Veterinária, 2004. p.217.

RUIZ, A.; FRENKEL, J. K.; CERDAS, L. Isolation of toxoplasma from soil. Journal of Parasitology, Lawrence, v.59, n.1, p.204-206, 1973.

SABIN, A. B.; FELDMAN, H. A. Dyes as microchemical indicators of a new immunity phenomenon affecting a protozoon parasite (T. gondii). Science, Washington, v.108, p.660-663, 1948.
SAGER, H.; MORET, C. S.; MÜLLER, N.; STAUBLI, D.; ESPOSITO, M.; SCHARES, G.; HÄSSIG, M.; STÄRK, K.; GOTTSTEIN, B. Incidence of Neospora caninum and other intestinal protozoan parasites in populations of Swiss dogs. Veterinary Parasitology, Amsterdam, v.139, n.1/3, p.84-92, 2006.

SALATA, E.; YOSHIDA, E. L. A.; PEREIRA, E. A.; CORREAA, F. M. A. Toxoplasmose em animais silvestres e domésticos da região de Botucatu, Estado de São Paulo, Brasil. Revista do Instituto de Medicina Tropical de SãoPaulo, v.27, n.1, p.20-22, 1985.

SALIBA, A. M.; FUEHS, H.; FREITAS, D. C. Toxoplasmose canina. Veterinário, São Paulo, v.5, n.1, p.35-41, 1958.

SANTOS, J.A.; NOVLOSKI, G.;PEREIRA,E.F.C.; REZENDE, A. M. L. Estudos sobre a incidência e as lesões histopatológicas da toxoplasmose em mamíferos domésticos (cães e coelhos) no Brasil. Pesquisa Agropecuária Brasileira, Rio de Janeiro, v.3, p.275-283, 1968.

SCHARES, G.; PANTCHEV, N.; BARUTZKI, D.; HEYDORN, A. O.; BAUER, C; CONRATHS, F. J. Oocysts of Neospora caninum, Hammondia heydorni, Toxoplasma gondii and Hammondia hammondi in faeces collected from dogs in Germany. International Jounal for Parasitology, Oxford, v.35, n. 14, p.1525-1537, 2005.

SCHATZBERG, S. J.; HALEY, N. J.; BARR, S. C.; LAHUNTA, A.; OLBY, N.; MUNANA, K.; SHARP, N. J. $\mathrm{H}$. Use of a multiplex polymerase chain reaction assay in the antemortem diagnosis of toxoplasmosis and neosporosis in the central nervous system of cats and dogs. American Journal of Veterinary Research, Chicago, v.64, n.12, p.1507-1513, 2003.

SCHWARZ, J. A.; FOUTS, A.; CUMMINGS, C. A.; FERGUSON, J. P.; BOOTHROYD, J. A novel rhoptry in Toxoplasma gondii bradyzoites and merozoites. Molecular and Biochemical Parasitology, Amsterdam, v.144, n.2, p.159-166, 2005.

SIBLEI, L.D; HOWE, D.K.; WAN, K.L; KHAN, S.; ASLETT, M.A.; AJIOKA, J.W.; Toxoplasma as a model genetic system. In: SMITH, D.F.; PARSONS, M. Molecular biology of parasitic protozoa. Oxford: Oxford University Press, 1995. p.55-74.

SILVA, A. V.; PEZERICO, S. B.; LIMA, V. Y.; MORETTI, L. D. A.; PINHEIRO, J. P.; TANAKA, E. M.; RIBEIRO, M. G.; LANGONI, H. Genotyping of Toxoplasma gondii strains isolated from dogs with neurological signs. Veterinary Parasitology, Amsterdam, v.127, n.1, p.23-27, 2005.

SILVA, L. A.; VIEIRA, R. S.; SERAFINI, L. N.; CARLOTTI JUNIOR, C. G.; FIGUEIREDO, J. F. C. Toxoplasmose do sistema nervoso central em paciente sem evidência de imunossupressão: relato de caso. Revista da Sociedade 
Brasileira de Medicina Tropical, Rio de Janeiro, v.34, n.5, p.487-490, 2001.

SILVEIRA, C.; BELFORT JÚNIOR, R.; MUCCIOLI, C.; ABREU, M. T.; MARTINS,.M. C.; VICTORA, C.; NUSSENBLATT, R. B.; HOLLAND, G. N. A follow-up study of Toxoplasma gondii infection in southern Brazil. American Journal of Ophtalmology, Chicago, v.131, n.3, p.351-354, 2001.

SOCCOL, V. T.; GUBERT, I. C.; CARZINO, L. C.; MASSUQUETTO, S. C.; SOCCOL, A. T. Prevalência de toxoplasmose em gestantes através da padronizaçäo da técnica de ELISA. Revista Médica do Paraná, Curitiba, v.61, n.1, p.15-17, 2003.

SOGORB, F.; JAMBA, L. F.; GUIMARÃES, E. C.; DEANE, M. P. Toxoplasmose espontânea em animais domésticos e silvestres, em São Paulo. Revista do Instituto de Medicina Tropical de São Paulo, São Paulo, v.14, n.5, p.314-320, 1972.

SOUZA PINTO, A. R.; PEREIRA, M. J. S.; ALMOSNY, N. R. P.; ALMEIDA, N. C. A. Análise multivariada dos fatores de risco associados á infecção por Toxoplasma gondii em cães atendidos na Policlínica da Universidade Federal Fluminense. In: CONGRESSO BRASILEIRO DE PARASITOLOGIA VETERINÁRIA, 13., 2004, Ouro Preto. Anais...Ouro Preto: Colégio Brasileiro de Parasitologia Veterinária, 2004a. p.215.

. Fatores de risco associados á infecção por Toxoplasma gondii em cães domiciliados e mantidos sob confinamento. In: CONGRESSO BRASILEIRO DE PARASITOLOGIA VETERINÁRIA, 13., 2004, Ouro Preto. Anais...Ouro Preto: Colégio Brasileiro de Parasitologia Veterinária, 2004b. p.216.

SOUZA, S. L. P.; GENNARI, S. M.; YAI, L. E. O.; D'AURIA, S. R. N.; CARDOSO, S. M. S.; GUIMARÃES JUNIOR, J. S.; DUBEY, J. P. Ocurrence of Toxoplasma gondii antibodies in sera from dogs of the urban and rural areas from Brazil. Revista Brasileira de Parasitologia Veterinária, São Paulo, v.12, n.1, p.1-3, 2003.

SPEER, C. A.; DUBEY, J. P. Ultrastructural differentiation of Toxoplasma gondii schizonts (types B to E) and gamonts in the intestines of cats fed bradyzoites. International Journal for Parasitology, Oxford, v.35, n.2, p.193-206, 2005.

SPLENDORE, A. Un nuovo protozoa parasita dei Gonigli incontrato nelle lesioni anatomiche d'una malattia chericorda in multipunti il Kala-Azar dell Uomo. Revista da Sociedade Scientifica de São Paulo, São Paulo, v.3, p.109-112, 1908.

SU, C.; ZHANG, X.; DUBEY, J. P. Genotyping of Toxoplasma gondii by multilocus PCR-RFLP markers: a high resolution and simple method for identification of parasites. International Journal for Parasitology, Oxford, v.36, n.7, p.841-848, 2006.

SUKTHANA, Y.; CHINTANA, T.; LEKKLA, A. Toxoplasma gondii antibody in HIV-infected persons. Journal of the Medical Association of Thailand, Bangkok, v.83, n.6, p.681-684, 2000.

SUTER, M. M.; HAUSER, B.; PALMER, D. G.; OETTLI, P. Polymyositis - polyradiculitis due to toxoplasmosis in the dog: serology and tissue biopsy as diagnostic aids. Zentralblatt fur Veterinarmedizin, Berlin, v.31, n.10, p.792798, 1984.

VARANDAS, N. P.; RACHED, P. A. A.; COSTA, G. H. N.; SOUZA, L. M.; CASTAGNOLI, K. C.; COSTA, A. J. Freqüência de anticorpos anti-Neospora caninum e contra Toxoplasma gondii em cães da região nordeste do Estado de São Paulo: correlação com neuropatias. Semina: Ciências Agrárias, Londrina, v.22, n.1, p.105-111, 2001.

WITTE, H. M.; PIEKARSKI, G. Die OocystenAusscheidung bei experimentell infizierten Katzen in Abhängigkeit vom Toxoplasma-Stamm. Zeitschrift fur Parasitenkunde, Berlin, v.33, n.4, p.358-360, 1970.

WOLF, A.; COWEN, D. Granulomatous encephalomyelitis due to an encephalitozoon (encephalitozic encephalomyelitis). A new protozoan disease of man. Bulletin of the Neurological Institute of New York, New York, v.6, p.306-371, 1937.

WOLF, A.; COWEN, D.; PAIGE, B. Human toxoplasmosis; occurrence in infants as an encephalomyelitis, verification by transmission to animals, Science, Washington, v.89, p.226-227, 1939.

YAI, L. E. O.; CAÑÓN-FRANCO, W. A.; GERALDI, V. C.; SUMMA, M. E. L.; CAMARGO, M. C. G. O.; DUBEY, J.P.; GENNARI, S. M. Seroprevalence of Neospora caninum and Toxoplasma gondii antibodies in the South American opossum (Didelphis marsapialis) from the city of São Paulo, Brazil. Journal of Parasitology, Lawrence, v.89, n.4, p.870-871, 2003.

YLMAZ, M.S.; HOPKINS, S.H. Effects of different conditions on duration of infectivity of Toxoplasma gondii oocysts. Journal of Parasitology, Lawrence, v.58, n.5, p. 938-939, 1972.

ZHANG, S.; WEI, M. X.; WANG, L. Y.; DING, Z. Y.; XU, X. P. Comparison a modified agglutination test (MAT), IHAT and ELISA for detecting antibodies to Toxoplasma gondii. Acta Parasitologica Medica Entomologica Sinica, China, v.8, n.4, p.199-203, 2001. 
